\title{
URBANISMO EM MINAS GERAIS: OLHARES DE ENGENHEIROS, ARQUITETOS, GEÓGRAFOS E OUTROS PLANEJADORES(1930-1980) ${ }^{1}$
}

\author{
Fabio Jose Martins de Lima
}

\section{Resumo}

O artigo contribui para a compreensão da atuação academica e do percurso profissional dos urbanistas relacionados à formação e a consolidaçao das cidades no estado de Minas Gerais. A abordagem parte do entendimento dos itinerarios academicos e profissionais dos urbanistas e a sua relaçao com as transformaçoes propostas para as cidades no arco temporal entre os anos 1930 e 1980. Aqui se coloca a recorrencia as teorias e as metodologias para o entendimento da historia do urbanismo, esta relacionada as praticas e ao pensamento sobre as cidades. Nesta abordagem a analise comparativa é importante para a apreensao do processo de desenvolvimento face as propostas de transformaçao elaboradas pelos tecnicos. Neste percurso, buscamos a continuidade de pesquisas anteriores voltadas para a compreensão da história do urbanismo e do planejamento urbano no Estado.

\section{Palavras-Chave}

Urbanismo, Historia do Urbanismo, Planejamento Urbano , Minas Gerais

\section{Abstract}

The paper contributes to understanding the role of academic and professionalitinerary of planners related the process of development of the cities in the state of Minas Gerais. The approach is based on the understanding of academic and professional

\footnotetext{
1 O texto configura-se como continuaçao de pesquisa que envolve incursoes nos acervos em Belo Horizonte e em acervos locais distribuidos no ambito estadual. Os trabalhos contam com a participaçao de pesquisadores colaboradores como Helena T. Creston, Barbara L. Barbosa, Bianca M. Veiga, Ana Paula L. P. Cruz, Antonio C. Boscariol, Larissa R. Moura, alem de alunos bolsistas, a saber, Taina de C. Lamoglia, Willian C. A. Mendonça, Danilo de L. Guimaraes, Aline M. F. Barata, Livea R. Pereira, Itala Karla, Debora V. Almeida, Marcela D. Fernandes, Analice V. D’Avila, Vitor Lima, Klinton de M. Barbosa Junior, Fernanda Portela, Marine Mattos. A partir de 2011 desenvolvemos Estagio Posdoutoral com o apoio da CAPES na Università IUAV di Venezia (IUAV), com o intuito de buscar fundamentos teoricos e metodologicos para a pesquisa sobre a historia do urbanismo. A pesquisa vincula-se, ainda, aos trabalhos da rede de pesquisa Urbanismo no Brasil 1900-1965. Versao do texto foi apresentado no 15 th IPHS Conference : "Cities, nations and regions in planning history", realizado em Sao Paulo, em 2012. Agradecemos o apoio da CAPES, do CNPQ, da FAPEMIG, do Ministerio das Cidades e do Ministerio da Cultura. Afiliação: Universidade Federal de Juiz de Fora ; fabio.lima@ufjf.edu.br.
}

URBANA, V.5, nº6, mar.2013 - Dossiê: Urbanistas e Urbanismo- CIEC/UNICAMP 
planners' itineraries and its relationship with the transformations proposed for cities in the period between the years 1930 and 1980. Here arises the recurrence theories and methodologies for understanding the history of urbanism is related to the practices and thinking about cities. In this approach the comparative analysis is important for the apprehension of the development process against the proposed transformation developed by technicians. In this way, we seek continuity of previous research focused on understanding the history of urbanism and urban planning in the State.

\section{Key-words}

Urbanism ,History of Urbanism, Urban Planning, Minas Gerais

\section{Introduçao}

O trabalho envolve a continuidade de pesquisas anteriores voltadas para a compreensão da história do urbanismo e do planejamento urbano em Minas Gerais, com vistas ao entendimento do processo historico e à fundamentaçao para o enfrentamento dos problemas urbanisticos na atualidade.Em outras palavras, para a reflexão sobre o futuro de nossas urbes torna-se necessário o entendimento, no passado e no presente, das práticas e do pensamento sobre as cidades. Por esta via, temos a compreensão de processos, na verdade, estes desencadeados sobre os municipios enfocados, seja na sua globalidade, seja sobre partes significativas do seu contexto urbano/rural. Para além dos municipios, em si mesmo, a relaçao com outros municipios do entorno, tendo em vista a definição de diretrizes urbanísticas para o desenvolvimento urbano e rural. ${ }^{2}$

As tramas e traçados municipais materializam processos de desenvolvimento e expansões urbanas e rurais. Por entre montes e vales, marginais aos cursos d'água, em áreas alagadiças, ou em encostas de difícil acesso, muitas vezes sujeitas a escorregamentos, os municípios avançaram as suas ocupações urbanas. Uma "evolução" que, de maneira clara e visível, não trouxe desenvolvimento para as

\footnotetext{
${ }^{2}$ A preocupacão com a preservação da memória de trajetórias de urbanistas em Minas Gerais e, particularmente, pela organização e controle do material documental, que possibilitou o entendimento destas trajetórias, teve início no processo de pesquisa desencadeado no ámbito da Rede Urbanismo no Brasil, a partir de 1995 e, posteriormente, em trabalhos de revisão e complementacão de dados no Núcleo de Pesquisa e Extensão Urbanismo em Minas Gerais da Universidade Federal de Juiz de Fora. Tal preocupação envolveu estudos e levantamentos sobre o passado, além de leituras empreendidas nos dias atuais - passado e presente com vistas ao futuro.
} 
localidades. Ao contrário, o que predominou foi o imprevisto, o inusitado por assim dizer, mesmo com as inumeras propostas e a serie deprojetos elaborados para as cidades, como se comprova pelas gerações de urbanistas que atuaram em Minas Gerais. Para além das propostas e dos projetos desenvolvidos, o que faltou foram gestões públicas eficientes e vontade política para a resolução dos problemas urbanos. E com certeza a mobilização e o envolvimento das comunidades também foi algo desprezado pelos administradores e tambem pelos planejadores.

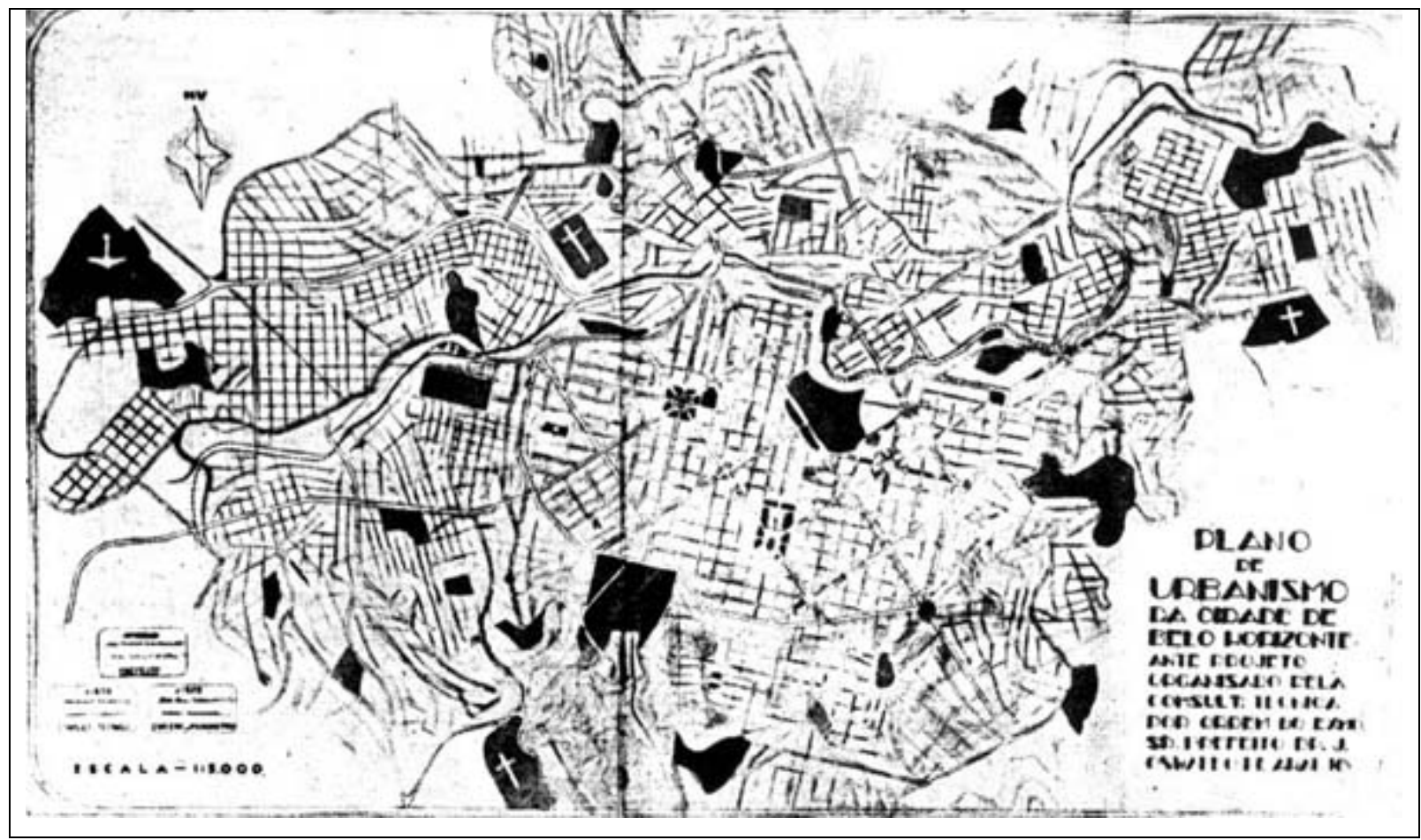

Figura 01-Plano de Urbanismo da Cidade de Belo Horizonte - Planta Geral, elaborado por Lincoln Continentino, apresentado a Comissao Tecnica Consultiva em 1934.

Fonte : Urbanismomg/UFJF.

O estudo da trajetória dos urbanistas nos remete, assim, a sua formação acadêmica e a sua atuação profissional, esta última com vínculos estabelecidos junto a administração pública e, na esfera privada, através de escritórios de engenharia e arquitetura. As proposições elaboradas pelos técnicos para as cidades, representadas por meio de desenhos e escritos, buscavam a materialização de uma "cidade moderna", cada qual com uma visão particular. Comparecem visões diferenciadas cujo pressuposto para a organização dos aglomerados urbanos - em termos de um ordenamento racional da expansão urbana - era o plano. Neste sentido, os planos 
urbanísticos projetavam uma realidade a ser alcançada, como uma projeção virtual de um novo modo de vida urbano. E estes planos eram referenciados, ou seja, dialogavam com outras experiências em termos de idéias que circulavam em fóruns de discussão, instituições de ensino, além de publicações. Outra forma de interlocução era "...através da contratação de técnicos para a elaboração de pareceres e de planos. Em alguns casos, estudos expostos em congressos desdobraram-se em planos. A contratação de especialistas incluiu de diversas formas os urbanistas estrangeiros. ${ }^{13}$ Neste sentido, traduções e apropriações de ideários urbanísticos se inserem nas propostas para as cidades, como resultado de intercâmbios culturais e artísticos, itinerários de estudos, ensino e pesquisa, tanto em termos da vinda de profissionais estrangeiros, quanto em termos da ida de brasileiros ao exterior. Vale ressaltar a instalação do Curso de Urbanismo na Escola de Arquitetura da, então, Universidade de Minas Gerais, em 1948, voltado para a formação profissional de urbanistas. O curso tinha a duração de dois anos e possibilitou o estudo sistemático das teorias para as intervenções sobre as cidades, acrescido de ciclos de conferências, como as ministradas por Gaston Bardet, durante quatro meses, nos anos 50. Estes itinerários proporcionavam a ampliação do olhar dos técnicos sobre os problemas urbanos.

O arco temporal definido para a pesquisa compreende duas frentes, entre os anos 1930 e 1980, numa perspectiva de análise comparada no período configurado pelo Estado Novo e pela Ditadura Militar. A primeira com as questões relacionadas com o processo de institucionalização e consolidação do urbanismo e do planejamento urbano junto à administração pública, a partir da capital do estado, Belo Horizonte. A segunda, voltada para o entendimento das interlocuções internacionais e nacionais dos urbanistas atuantes neste período, inclusive à frente de órgãos municipais e estaduais. Ressaltamos órgãos e comissões municipais ainda por serem melhor explorados, como a Comissão Técnica Consultiva de Belo Horizonte, criada em 1934, e o Serviço do Plano Diretor, dos anos 1960, no âmbito municipal. No âmbito estadual, neste período, temos a ação de órgãos especializados, tais como a Divisão de Negócios Municipais da Secretaria do Interior, ou o Serviço de Saneamento e Urbanismo da Secretaria de Estado dos Negócios, da Viação e Obras Públicas, os serviços de Estâncias Hidro-minerais do estado e o Departamento Estadual de Saúde. A partir de 1969 a criação da Fundação João Pinheiro e no seguimento o planejamento metropolitano de Belo Horizonte com a PLAMBEL. Estas duas frentes, como

\footnotetext{
${ }^{3}$ LEME, M. C. da S. (org.). Urbanismo no Brasil: 1895-1965. São Paulo: Studio Nobel; FAUUSP; FUPAM,
} 1999, p.26. 
mencionado, sobre os órgãos de planejamento em Minas Gerais e sobre as interlocuções dos urbanistas que atuaram nos departamentos e comissões, merecem estudos específicos, o que buscamos com esta contribuição.

Em termos metodologicos os estudos comparativos, ou melhor dizendo, a analise comparada incide sobre os conceitos e temas relacionados às trajetorias dos urbanistas e aos casos de intervençoes, seja em termos parciais sobre tecidos existentes, seja em temos de novas cidades planejadas. O interesse por aprimorar os enfoques metodologicos perpassa as aproximaçoes sobre o pensamento e as praticas sobre as cidades. De um lado temos textos que discutem e apresentam as propostas e planos, de outro lado, a propria atuaçao dos urbanistas, atraves da sua experiencia profissional e academica. Como "pano de fundo" as teorias do urbanismo, com as suas vertentes possiveis de vinculaçoes e o ideario em termos de pensamento que as sustenta. As aproximaçoes desenvolvidas sobre estes temas tem sido importantes para a compreensao do pensamento urbanistico e das praticas sobre as cidades em Minas Gerais, particularmente para o entendimento da visao dos urbanistas e das estrategias para o enfrentamento dos problemas urbanos. ${ }^{4}$ Ao mesmo tempo, tem permitido o entendimento da complexidade inerente ao processo de desenvolvimento das cidades. Neste sentido, a noçao de aproximaçoes sucessivas sobre determinados horizontes historicos, numa perspectiva cronologica, sobre os diversos momentos que caracterizam a historia, a historia das cidades em particular. Vale ressaltar que, nestes enfoques,as analises levam em conta o contexto especifico espaço-temporal em que as cidades se vinculam. A questao crucial, neste caso, que comparece inicialmente é entender onde e quando os processos ocorreram. ${ }^{5}$ Ao mesmo tempo deve ser ressaltada,como chaves de interpretaçao, a importancia de serem evidenciados os momentos de mudança nestes processos. ${ }^{6}$

\footnotetext{
4 Temos apresentado comunicaçoes e paineis em eventos para divulgar os resultados da pesquisa. Ao mesmo tempo temos publicado livros e capitulos de livro com passagens relacionadas a tematica aqui enfocada. Em 2012 publicamos capitulo de livro sobre o caso de Monlevade e apresentamos comunicaçao no 15 IPHS Conference, realizada em Sao Paulo. Ainda em 2012, no ambito do Estagio Posdoutoral em Venezia temos discutido questoes metodologicas e encaminhado publicaçoes de resultados parciais. Nas referencias bibliograficas inserimos o material documental resultante dos trabalhos de pesquisa.

${ }^{5}$ De acordo com Guico Zucconi, esta é a primeira interrogaçao a ser feita, para o estudo da historia das cidades. ZUCCONI, G. notas de aulas IUAV cursos de Storia della Città.

${ }^{6}$ De acordo com Donatella Calabi, a na serie de ferramentas e estrategias de interpretaçao da historia das cidades. CALABI, D. notas de aulas IUAV cursos de Storia della Città.
} 


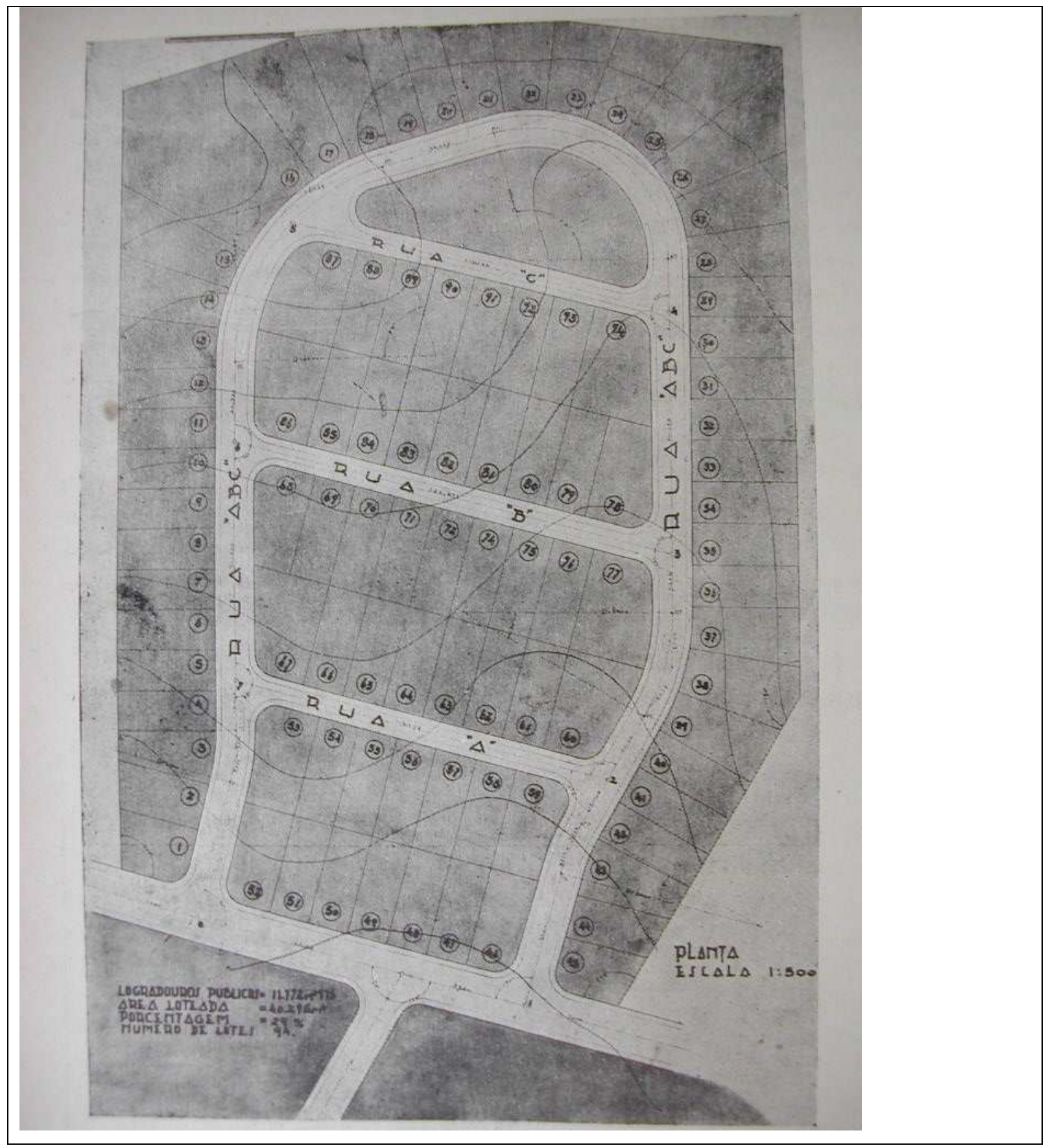

Figura 02 - Esquema de parcelamento elaborado por Sylvio Aldighieri, cerca de 1940. Fonte : Urbanismomg/UFJF.

O tempo aqui considerado como fonte de mudanças e continuidades, para a historia das cidades, particularmente para a historia do urbanismo, e cada momento 
como uma sintese de tempos convergentes. ${ }^{7}$ Mais uma vez ressaltamos que os estudos não partem de uma perspectiva de análise linear, ou seja, não pensamos os fatos encadeados numa linha do tempo de maneira evolutiva. Ao mesmo tempo, não temos a pretensão de esgotar as possibilidades de abordagem do tema e das questões correlatas, pela consciencia presente das nossas próprias limitaç̃ões e dificuldades. As lacunas, em alguns dos casos podem ser resolvidas com hipóteses a serem comprovadas com novos documentos ou pela trama que se constrói com os documentos disponíveis. O que se busca é um enfoque particular, ou seja, uma interpretação sobre os fatos, como uma contribuição que não se esgota na incursão em si mesma. Assim, a produção dos técnicos no Estado de Minas Gerais e o próprio processo de formação das cidades mineiras - relacionado ao urbanismo e ao planejamento urbano, merecem outras aproximaç̃os.

Neste sentido, buscamos explicaç̃ões, não a partir de um começo remoto, isto é, tendo um ponto original longínquo para os fenómenos analisados. Em outras palavras, não temos a intenção de uma busca das origens para o encaminhamento da pesquisa. Pelo contrário, com as leituras empreendidas a partir da documentação levantada buscamos fundamentaç̃ões, com o sentido de uma introdução e a composição de um quadro de referencias para o trabalho. E, neste sentido se coloca também o aspecto interminável dos fatos históricos, sem a premissa das relacões de causa e efeito, tendo em vista as permanéncias e as mudanças decorrentes das transformações ao longo do tempo. Assim temos antecedentes analisados como instrumentos para o conhecimento histórico, alguns mais particulares, outros mais gerais, com os seus desdobramentos possíveis. E vale mencionar ainda que a pesquisa não tem o intuito de enumerar soluções a partir das experiéncias relatadas, ao contrário, pretendemos recolocar questões já vivenciadas, para um melhor posicionamento na atualidade, ou seja, o que foi pensado para as cidades se coloca, assim, como um referencial de trabalho, a ser considerado nas difíceis tarefas do presente, face às complexidades dos problemas urbanos a nos desafiar.

\section{O urbanismo como disciplina e pratica profissional}

A compreensão da institucionalização e da consolidação do urbanismo e do planejamento urbano no Estado, perpassa o estudo de experiências diversificadas,

\footnotetext{
${ }^{7}$ FERNANDES, A. \& GOMES, M. A. A. de F. A pesquisa recente em história urbana no Brasil: percursos e questões. In: PADILHA, N. (org.). Cidade e Urbanismo: história, teorias e práticas. Salvador: Mestrado em Arquitetura e Urbanismo da FAUFBa, 1998, pp.13-28.
}

URBANA, V.5, no6, mar.2013 - Dossiê: Urbanistas e Urbanismo- CIEC/UNICAMP 
propostas parciais para partes significativas de cidades, proposições integrais de novas cidades, intervenções em ambientes pré-existentes ou "in natura". As propostas idealizadas em sua grande maioria nao foram totalmente realizadas, muitas delas permaneceram no papel. Vale ressaltar alguns exemplos de cidades, como no caso de Belo Horizonte, com ações de planejamento, a mais recente marcada pelo Plano Diretor da cidade, cuja aprovação, em 1996, compreendeu um processo que envolveu a participação comunitária. Planejadas ou não, nos casos estudados temos importantes referenciais sobre a atuação dos urbanistas de maneira individual e/ou em grupos de trabalho. A investigação sobre as instituições e as interlocuções dos urbanistas permitiu aproximações sobre as vertentes urbanísticas em jogo no período delimitado para este enfoque. Também se coloca a relação com o que foi feito nas primeiras décadas do século $\mathrm{XX}$, para atestarmos as permanências e descontinuidades no tocante às práticas urbanísticas. De um lado, transposições de modelos aplicadas à realidade local, de outro lado, desdobramentos resultantes do ensino do urbanismo que remonta ao final dos anos 40, na Escola de Arquitetura da Universidade de Minas Gerais, atual Universidade Federal de Minas Gerais, e interlocuções com outros centros de ensino e pesquisa. Entre os anos 30 e 80, temos ações efetivas para a instrumentalização do estado e da sua capital para o enfrentamento dos problemas de urbanismo e de planejamento urbano e regional, com inumeras interlocuções dos técnicos. Como marcos temporais, a Comissão Técnica Consultiva de 1934 e a criação de órgãos como a Fundação João Pinheiro e o PLAMBEL no final dos anos 60 e meados de 70, respectivamente. O entendimento sobre o passado recente do estado nos parece essencial para pensarmos os rumos futuros no tocante ao planejamento em Minas Gerais. 


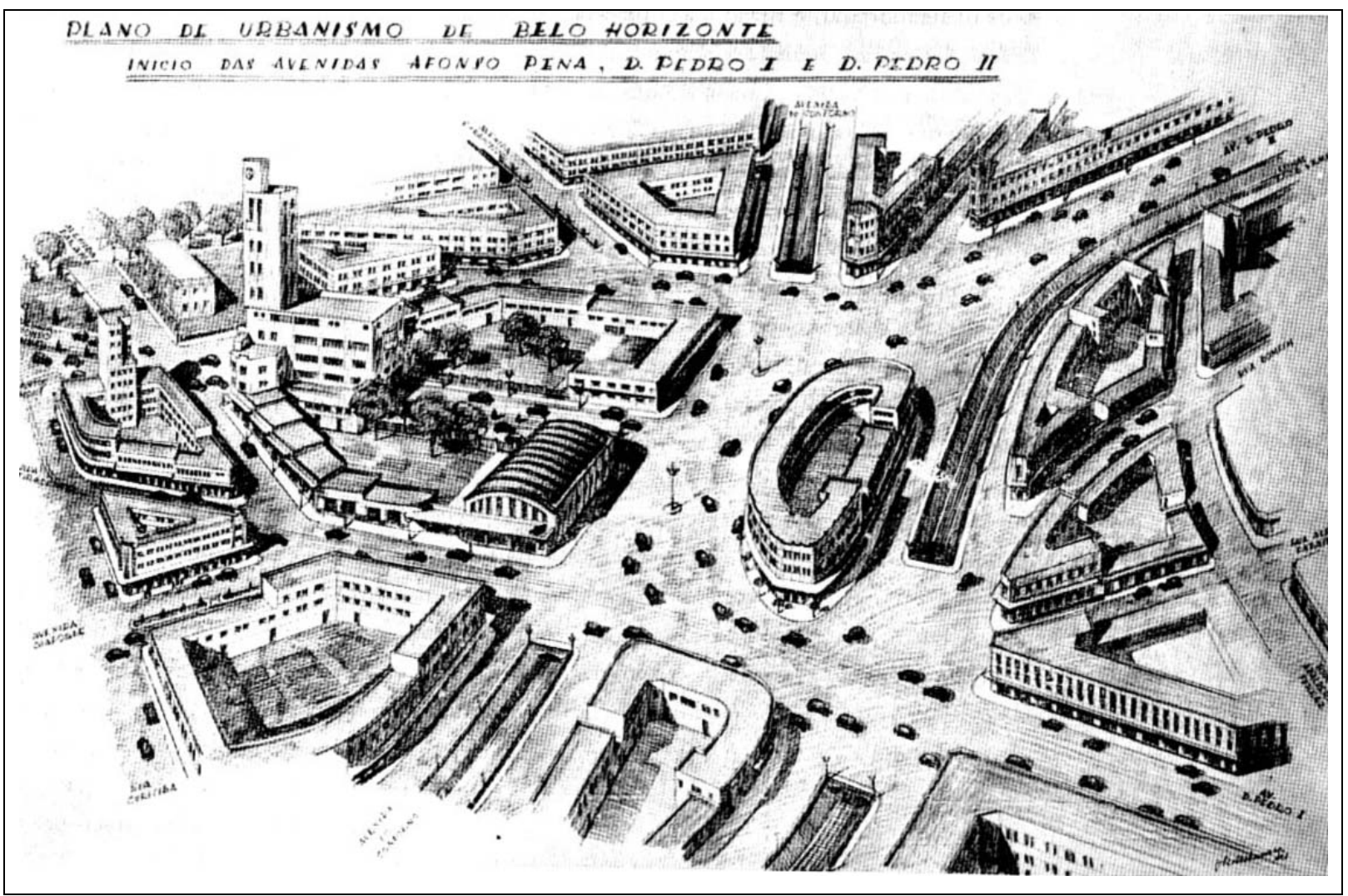

Figura 03 - Plano de Urbanismo da Cidade de Belo Horizonte - Perspectiva, elaborado por Lincoln Continentino, apresentado a Comissao Tecnica Consultiva em 1934. Fonte : Urbanismomg/UFJF.

Em Belo Horizonte as transformações se deram com rapidez e intensidade, alterando, a paisagem bucólica pensada pelos seus idealizadores, Aarão Reis e Francisco Bicalho, que estiveram à frente da Comissão Construtora da Nova Capital, ainda no final do século XIX. Também foram intensas as mudanças implementadas sobre o espaço urbano das cidades do interior do Estado. Expansões desenfreadas, aberturas de novas vias, edificações que se multiplicaram, enfim, horizontes estendidos sem planejamento que ampliaram e tornaram mais difíceis de solucionar os problemas urbanos. Neste sentido, entender a institucionalização do urbanismo e do planejamento urbano, numa perspectiva de análise comparada sobre o que foi proposto para as cidades, assim como as interlocuções com o intuito de capacitação dos urbanistas, nos parece essencial. O que foi pensado para os municípios, em termos de urbanismo e planejamento urbano, está diretamente relacionado ao que foi discutido e proposto no âmbito dos órgãos estaduais e municipais. Concepções URBANA, V.5, n6, mar.2013 - Dossiê: Urbanistas e Urbanismo- CIEC/UNICAMP 
distintas de cidade se inserem através de gerações de urbanistas voltadas para a melhoria das condições de vida, com a ênfase inicial para as questões de saneamento ede melhoramentos urbanos, ampliadas para a visão global, através de planos de urbanismo e legislações urbanísticas. Os tecnicos atuaram de maneira diversificada, seja vinculados a órgãos públicos, seja na iniciativa privada ou mesmo em instituições de ensino. De qualquer modo, "...a dupla inserção profissional: em instituições de ensino e nos órgãos públicos. (...) Estes dois vínculos estão na origem desta profissão e se mantém até hoje. Estabelecem relações entre os sistemas de chefias nos orgãos públicos e as antigas cátedras das escolas e faculdades e, se não resolve $o$ descompasso entre o proposto e o realizado, mantém este tema em permanente debate. ${ }^{18} \mathrm{Na}$ primeira metade do século $\mathrm{XX}$, a penetração da disciplina do urbanismo nas instituições públicas revela-se através de olhares de engenheiros, arquitetos e outros planejadores. Com isso, temos o aperfeiçoamento e o rigor científico da técnica voltada para a compreensão dos problemas urbanos e a sua resolução através de planos urbanísticos.

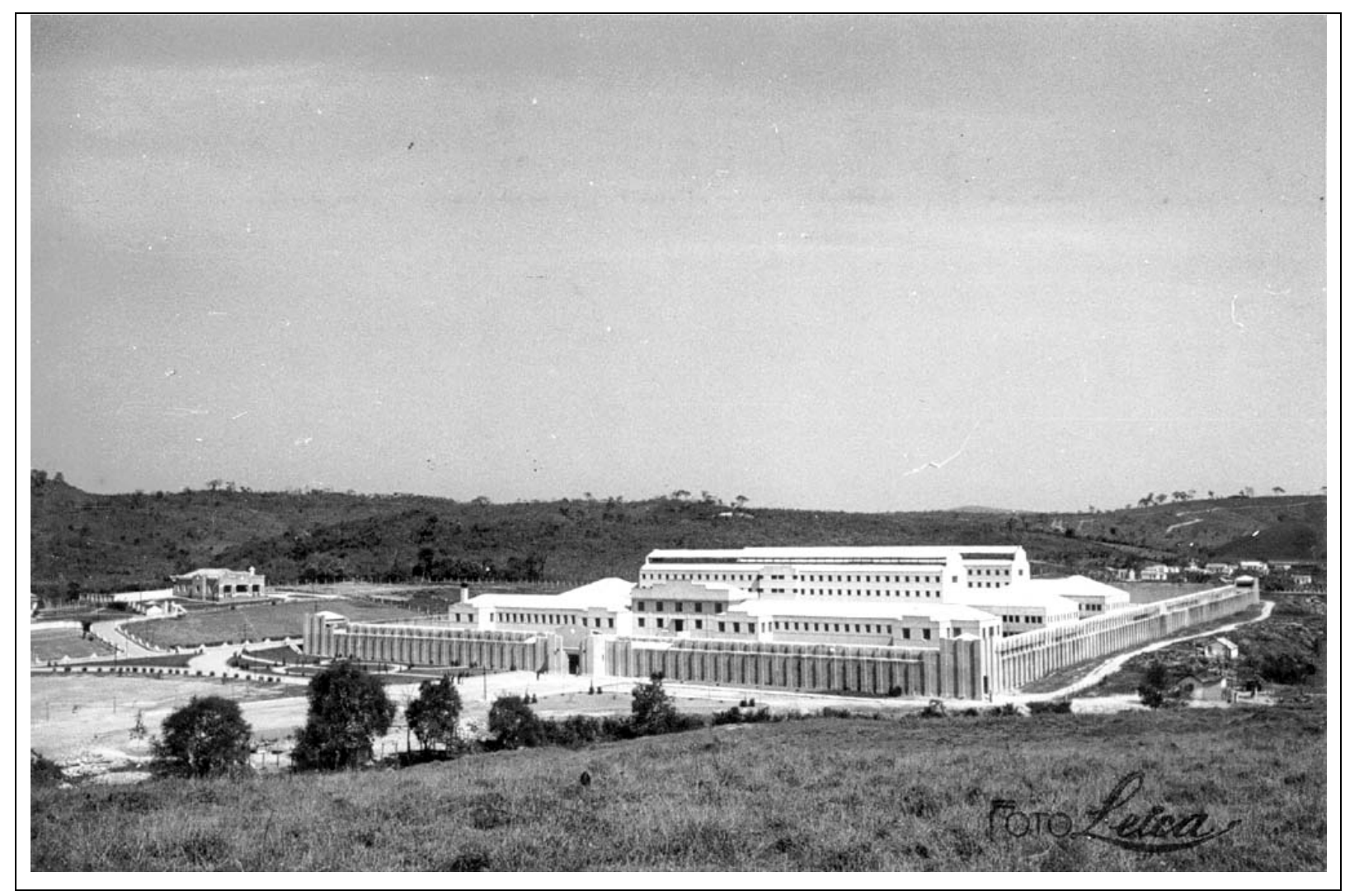

Figura 04 - Penitenciaria Agricola de Neves - vista geral, elaborado por Angelo Murgel, em

${ }^{8}$ LEME, M. C. da S. (1999) Urbanismo no Brasil: 1895-1965. São Paulo: Studio Nobel; FAUUSP; FUPAM URBANA, V.5, nº6, mar.2013 - Dossiê: Urbanistas e Urbanismo- CIEC/UNICAMP 
1932. Fonte : Urbanismomg/UFJF.

Vale destacar ainda que a reforma administrativa implementada na era Vargas incluiu mudanças, de acordo com Feldman, visando a modernização do serviço público federal. Ainda de acordo com Feldman, "...ao se analisar as instituições de urbanismo criadas no Brasil entre os anos 30 e os anos 60, podemos observar que esse período se caracteriza por movimentos de naturezas diversas que têm em comum a proposição de novas abordagens de gestão municipal. No campo do urbanismo é o período de institucionalização do planejamento como função de governo, que terá na criação do SERFHAU- Serviço Federal de Habitação e Urbanismo, em 1964, um marco importante, por se estabelecer, pela primeira vez, condições para criação de órgãos de planejamento municipais a partir da esfera federal. "9 Vale mencionar, ainda de acordo com Feldman, que "...as instâncias estaduais de controle e assistência aos municípios e as comissões consultivas junto às administrações municipais, criadas no contexto do governo provisório, constituem espaços de atuação dos urbanistas brasileiros para introdução de novas concepções urbanísticas - principalmente as originárias do urbanismo americano -, que serão de fundamental importância para o processo de legitimação e construção de um campo específico de exercício da profissão de urbanista na administração pública. "10

Podemos dizer que a institucionalização do urbanismo como disciplina e prática profissional, no final dos anos 20 e início dos anos 30, ocorreu bem antes da implementação destes cursos. As administrações municipais buscavam uma adequação às necessidades de propostas voltadas para o controle urbanístico das cidades.

Vale mencionar que a repercussão, no âmbito dos municípios mineiros, do que ocorria em Belo Horizonte - a moderna capital planejada ainda no século XIX sempre foi muito grande. Nas primeiras décadas do século $X X$, os debates em torno das questões de Urbanismo se vinculavam, inicialmente, à tradição ligada aos trabalhos de Engenharia Sanitária, dentre os quais destacamos aqueles inseridos nas trajetórias de engenheiros como Lourenço Baeta Neves e Lincoln de Campos Continentino. Neves dirigiu a Comissão de Melhoramentos Municipais, entre 1911 e 1914, tendo desenvolvido várias propostas de intervenção para pequenas e médias

\footnotetext{
${ }^{9}$ FELDMAN, Sarah. As instituições de urbanismo no Brasil : espaços de intermediação entre pensamento e prática. VII SEMINÁRIO DE HISTÓRIA DA CIDADE E DO URBANISMO. Salvador: PPGAU/FAU/UBA, 2002.

${ }^{10}$ FELDMAN, Sarah. As instituições de urbanismo no Brasil : espaços de intermediação entre pensamento e prática. VII SEMINÁRIO DE HISTÓRIA DA CIDADE E DO URBANISMO. Salvador: PPGAU/FAU/UBA, 2002.
} 
cidades do Estado. Esta comissão foi criada com o intuito de dar suporte técnico aos administradores públicos, através do estudo das obras de saneamento e melhoramentos dos municípios. Já Continentino teve uma vasta atuação, com propostas para diversas cidades mineiras, além da elaboração de um plano de urbanismo para a Capital, desenvolvido a partir de 1934. Além da plena atuação em Belo Horizonte, levantamos propostas para as cidades de Além Paraíba e Porto Novo, distrito desta, Barbacena, Belo Vale, Boa Esperança, Capitólio, Curvelo, Diamantina, Governador Valadares, Januária, João Monlevade, Itajubá, Pirapora, Poços de Caldas, Prata, São Lourenço e Vigia. Neves e Continentino também integraram os quadros da Comissão Técnica Consultiva, o primeiro, como presidente, e, o segundo, junto à subcomissão de Arquitetura e Urbanismo. O objetivo principal desta comissão era orientar a administração pública municipal de Belo Horizonte, quanto à implementação do plano da cidade.

Nos anos 30, acrescida à intensa discussão dos problemas urbanos, a busca de uma linguagem moderna impõe-se à Capital Mineira e se difunde pelas cidades do interior. Em Belo Horizonte, a impossibilidade do desenvolvimento planejado da cidade se revelava por uma expansão desenfreada da urbe. Neste período, se coloca a emergência de uma postura mais crítica com relação ao plano, além de novas oportunidades de formação profissional e de novos fóruns onde a cidade passa a ser discutida e reproposta. Ao mesmo tempo que se discutem os rumos da cidade numa visão global, consolida-se o processo de renovação da arquitetura da cidade, na busca de um "estilo moderno". A modernidade já anunciada com o art déco - conhecido como estilo cubista, futurista ou simplesmente moderno - se introduziria por meio de intervenções pontuais, que alterariam a fisionomia dos centros urbanos. Aos poucos estas transformações acenturariam o contraste entre a tradição e a contemporaneidade.

Temáticas distintas foram abordadas em intervenções pontuais, planos de expansão e propostas para a criação de cidades novas. Vertentes diferenciadas do urbanismo moderno comparecem, em muitos dos casos, conjugadas de maneira simultânea. Assim constatamos pela análise da realização de conjuntos como os bairros da Pampulha e da Cidade-Jardim Eldorado em Belo Horizonte/M.G., e, mesmo, proposições de cidades novas como foi o caso de Monlevade/M.G., esta por iniciativa da Companhia Siderurgica Belgo-Mineira. Enquanto para os equipamentos propostos sobressaiu uma linguagem moderna, materializada pelos partidos adotados e amplos espaços públicos criados, os planos de conjunto revelavam inspirações em outros modelos, como o ideário garden-city, tendo o sistema viário adaptado aos sítios de URBANA, V.5, nº6, mar.2013 - Dossiê: Urbanistas e Urbanismo- CIEC/UNICAMP 
implantação como um dos principais aspectos. Além disso, as intervenções propostas, particularmente aquelas que envolveram a inserção de objetos urbanos de grande porte, ocorreram em estruturas já consolidadas. Neste sentido, constata-se que a modernização das cidades, em muitos dos casos, foi implementada através de projetos arquitetônicos desconectados de um planejamento global. Mesmo assim, não se pode desprezar o impacto destas intervenções, na dinâmica urbana, e o significado das mesmas nas transformações urbanísticas, ainda mais em se tratando de pequenas e médias cidades. Os novos conceitos de cidade embutidos nestas proposições passavam a fazer parte da rotina dos moradores e do discurso dos seus administradores públicos. Afinal, por meio destas intervenções, ocorria a modificação do panorama das cidades, pela nova linguagem das edificações inseridas no conjunto urbano, bem como pela qualidade e característica diferenciadas dos seus espaços públicos, o que ampliava o espaço da rua tradicional e alterava a lógica fragmentada das ocupações urbanas.

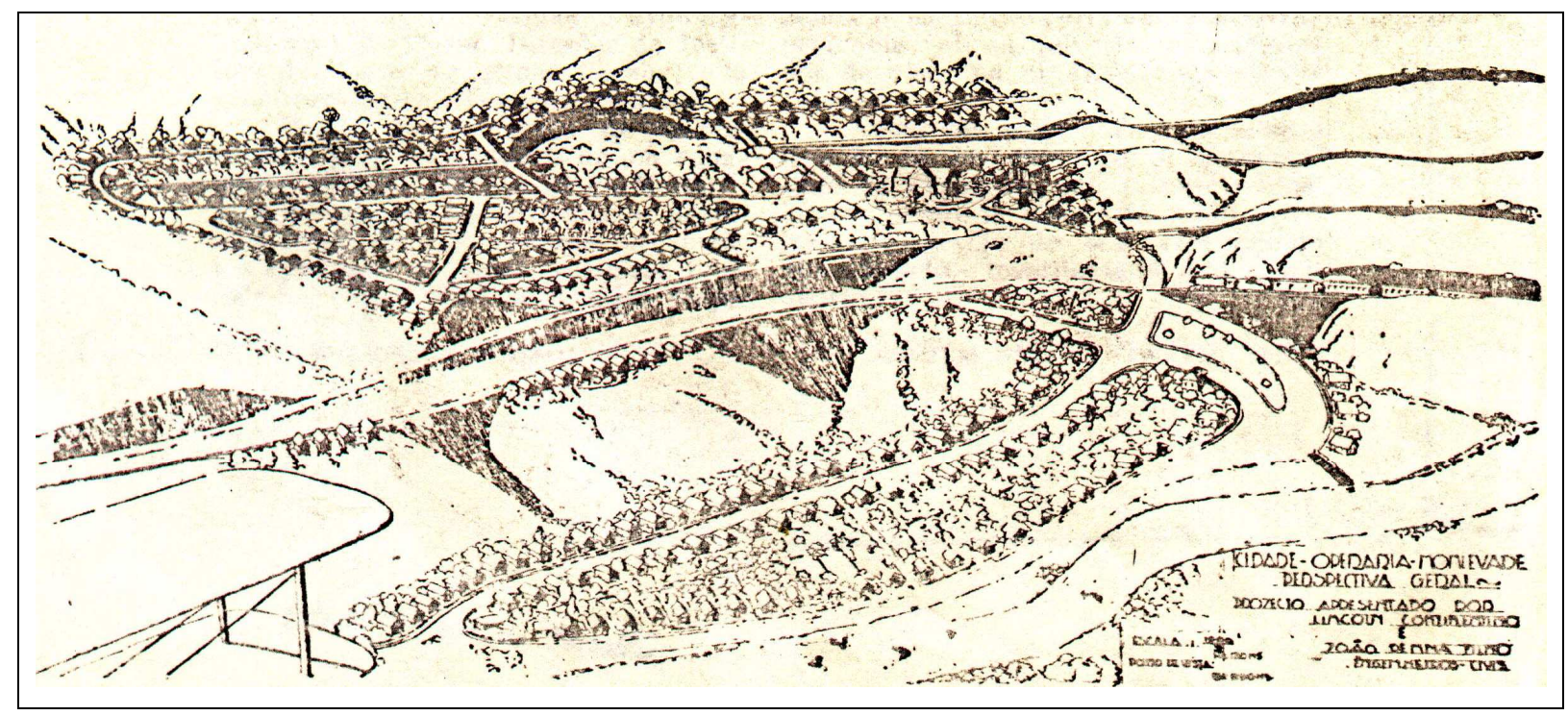

Figura 05 - Cidade Operaria Monlevade - Perspectiva Geral, por Lincoln Continentino, no concurso promovido pela Companhia Siderurgica Belgo Mineira, em 1934.

Fonte : Urbanismomg/UFJF.

Paralelamente ao extenso leque de proposições estudadas, algumas realizadas, outras não, se inseriam debates e palestras que reforçavam o papel do arquiteto nas intervenções sobre as cidades. Por esta via, se coloca a importância de cursos como foi o caso Escola de Arquitetura da então Universidade de Minas Gerais, atual Universidade Federal de Minas Gerais, e mesmo a Escola de Engenharia desta mesma 
universidade, além das publicações deste centros, na difusão de conceitos e experiências do urbanismo. Entretanto, grande parte das intervenções sobre as cidades não estavam atreladas a planos de conjunto, de acordo com as regras do urbanismo moderno. Neste sentido, constata-se também que diferentemente da preocupação teórica abrangente dos engenheiros - que buscavam uma definição para o urbanismo como disciplina e se especializavam neste campo - os arquitetos, com poucas exceções, não demonstravam interesse nestas questões mais amplas relacionadas com o objeto de estudo constituído pelas cidades. Nos anos 60, a atuação de grupos de urbanistas como foi o caso do processo desencadeado pela Sociedade para Análise Gráfica e Mecanográfica Aplicada aos Complexos Sociais SAGMACS em Belo Horizonte insere novos conceitos $e$ instrumentaliza as administrações municipais com mecanismos de planejamento em termos de planos diretores. A participação de profissionais de outras áreas neste processo contribuiu para a ampliação dos olhares e enfoques de planejamento urbano. Outros escritórios, compostos por arquitetos e profissionais de outras áreas, como o INTERPLANUS, também atuaram no Estado. Ainda em 1969, a criação da Fundação João Pinheiro, como uma instituição do governo do Estado, teve o papel de propiciar um órgão específico de planejamento voltado para as demandas das cidades mineiras. Já a autarquia PLAMBEL (Planejamento da Região Metropolitana de Belo Horizonte) entidade de planejamento e apoio técnico aos Conselhos Deliberativo e Consultivo foi instituída em 1975 e atuou como órgão intermediador de recursos do governo federal aos órgãos setoriais e municípios durante a década de 1970. Entre 1975 a 1980, o PLAMBEL atuou numa tentativa de consolidação de planejamento metropolitano e na elaboração de inúmeros projetos, sendo um órgão de âmbito metropolitano que deveria orientar o planejamento urbano e regional dos municípios. 


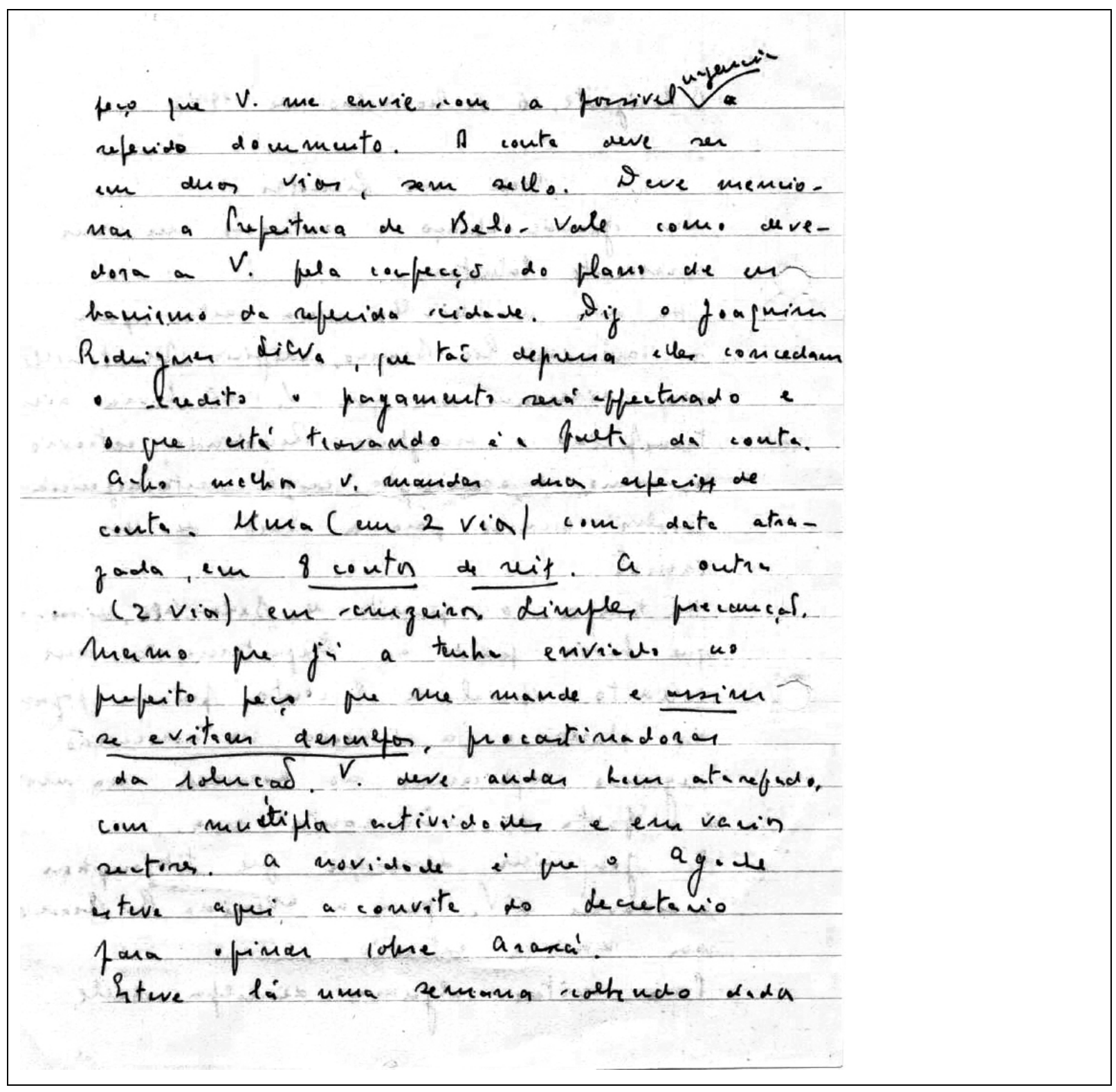

Figura 06 - Trecho de correspondencia sobre o Plano de Urbanismo de Belo Vale, por Lincoln Continentino, cerca de 1944. Fonte : Urbanismomg/UFJF.

\section{Consideraçoes Finais}

O estudo sobre a trajetoria dos urbanistas e as repercussoes sobre as cidades das proposiçoes elaboradas por estes profissionais, no periodo aqui delineado, tem revelado as especificidades relacionadas aos campos disciplinares do urbanismo e do planejamento urbano em Minas Gerais. De um lado temos pontos comuns ao que ocorre no Brasil e de outro lado aspectos locais e singulares, que permitem traçar o processo configurado nos horizontes de Minas Gerais. Dos profissionais atuantes em Belo Horizonte e, mesmo, nas cidades do estado, listamos os seguintes técnicos, a 
começar pelos engenheiros, advogados e arquitetos vinculados à Comissão Construtora da Nova Capital, Aarão Leal de Carvalho Reis, Francisco de Paula Bicalho, como engenheiros chefes sucessivamente e, em ordem alfabética Adalberto Dias Ferraz da Luz, Adolpho Pereira, Alfredo Camarate, Américo de Macedo, António do Prado Lopes Pereira, Bernardo Joaquim Figueiredo, Caetano César de Campos, Cícero Ribeiro Ferreira Rodrigues, Edgard Nascentes Coelho, Eugenio de Barros Raja Gabaglia, Fábio Nunes Leal, Francisco Saturnino Rodrigues de Brito, Hermillo Alves, Jean Marie Joseph Verdussem, José de Carvalho Almeida, José de Magalhães, Júlio César da Silva, Ludgero Wandick Dolabella, Luiz Olivieri, Luiz Martinho de Moraes, Manoel da Silva Couto, Paul Villon, Pedro de Nobrega Sigaud, Pedro Noel Sicard e Samuel Gomes Pereira. Muitos destes profissionais irão se fixar na capital ou no interior do estado, com trabalhos mais ligados ao campo da construção civil. Dentre estes, vale ressaltar a atuação de Francisco Saturnino Rodrigues de Brito que irá se destacar como urbanista, com inúmeras propostas para as cidades brasileiras configurando extensa obra teórica e prática. Em Minas Gerais levantamos propostas deste engenheiro para Juiz de Fora e para Uberaba, dentre outras.

Além dos profissionais vinculados à Comissão Construtora, destacamos os técnicos atuantes no campo do urbanismo em Belo Horizonte, na primeira metade do século, a saber, Lourenço Baeta Neves, Lincoln de Campos Continentino, Danilo Francisco Ambrósio, Ismaília de Moura Nunes, Martim Francisco Coelho Andrada, Paulo Gaetani, Walter Machado e Radamés Teixeira da Silva. Dentre estes, merece destaque as atuações de Lourenço Baeta Neves, discípulo de Francisco Saturnino Rodrigues de Brito, e do seu próprio discípulo, Lincoln de Campos Continentino. Baeta Neves desenvolverá inúmeros trabalhos no campo da Higiene Urbana para Belo Horizonte e para as cidades do interior do Estado. Do mesmo modo Lincoln Continentino seguirá os seus passos com propostas urbanísticas para a capital e também para as cidades do interior, com énfase para o planejamento através de planos de urbanismo. Além destes profissionais destacamos outros técnicos listados na sequéncia da continuidade dos levantamentos, que também trafegaram pelo campo do Urbanismo em Minas Gerais, como Francisco Baptista de Oliveira, Angelo Alberto Murgel, Sylvio Aldighieri, José Otacílio de Saboya Ribeiro, Francisco Bolonha, Lucio Costa, Oscar Niemeyer, Arthur Arcuri, Sergio Bernardes, Raphael Hardy Filho e Joany Machado. Ainda ressaltamos a participação de geógrafos como foi o caso de Roger Teulières e outros profissionais vinculados a empresas de planejamento, como foi o caso da SAGMACS mencionada anteriormente, com nomes como de Celso Lamparelli, dentre outros. 
Por fim, vale mencionar o processo multifacetado de penetração de ideários através de temas distintos e profissionais com formaç̃̃es diferenciadas. Intervenc,ões pontuais, planos de expansão e propostas para a criação de cidades novas inserem vertentes diferenciadas do urbanismo, em muitos dos casos, conjugadas de maneira simultanea. As proposições, algumas realizadas, outras não, serviram para a inserção de debates e palestras que reforçavam o papel do arquiteto nas intervenções sobre as cidades. Alem dos arquitetos, geografos, advogadose engenheiros outros profissionais irão se preocupar com os rumos futuros das cidades. Outros olhares interferem, assim, de maneira progressiva, para ampliação dos horizontes da cultura urbanística em Minas Gerais.

\section{Agradecimentos}

CAPES ; CNPq ; FAPEMIG ; Ministério das Cidades; Ministério da Cultura ; Ministério da Educação .

\section{Referências Bibliográficas}

ALEXANDER, C.. (1976) Une expérience d'urbanisme démocratique (Traduit de I'anglais par Robert Davreau et Amélie Petita). Paris: Éditions du Seuil, Título original The Oregon Experiment, 1975.

ARGAN, G. C. A. (1993) História da Arte como História da Cidade (tradução de

Pier Luigi Cabra). São Paulo: Martins Fontes, título original: Storia dell'Arte come Storia della Città (1984).

AYMONINO, Carlo. (1972) Origenes y desarrollo de la ciudad moderna.

Barcelona: Editorial Gustavo Gilli, título original: "Origini e sviluppo della città moderna".

Belo HORIzONTE. (1996) Plano Diretor do Município. Belo Horizonte Horizonte: Prefeitura Municipal de Belo Horizonte.

BenEVOlO, L. (1984) A Cidade e o Arquiteto (tradução de Rui Eduardo Santana Brito). São Paulo: Martins Fontes, título original "La Cittá e I'Architetto".

- (1981) Origens da Urbanística Moderna (tradução de Conceição Jardim e Eduardo L. Nogueira). Lisboa: Editorial Presença, título original: "Le origini dell 'Urbanistica Moderna". 
BLOCH, M. Introdução à História. (1976) Mira-Sintra: Publicações EuropaAmérica, $3^{a}$ edição, , título original "Apologie pour I'histoire ou Métier d'historien", 1941, tradução de Maria Manuel Miguel e Rui Grácio.

BRAUDEL, F. (1992) Escritos sobre a História (tradução de J. Guinsburg e Tereza Cristina Silveira da Mota).São Paulo: Editora Perspectiva, 2a Edição, título original: "Écrits sur I'Histoire" (1969).

CALABI, D. (2005) Storia della citta: I'eta contemporanea. Venezia: Marsilio. . (2004) Storia dell'urbanistica europea: questioni, strumenti, casi esemplari. Milano: Bruno Mondadori.

. (1997) Parigi anni venti: Marcel pöete e le origini della storia urbana. Venezia: Marsilio editori.

CARDOSO, C. F. S. (1994) Uma introdução à História. São Paulo: Brasiliense.

CARDOSO, I. (2001)Para uma crítica do presente. São Paulo: USP, Curso de PósGraduação em Sociologia, Ed. 34.

CERTEAU, M.de. (2006) A escrita da História (tradução de Maria de Lourdes Menezes). Rio de Janeiro: Forense Universitária, título original: "L'Écriture de I'Histoire"(1975).

CHOAY, F. (1979) O urbanismo: utopias e realidades, uma antologia (tradução de Dafne Nascimento Rodrigues). São Paulo: Editora Perspectiva, título original: "L'Urbanisme: Utopies et Réalités, Une Antologie", (1965).

.(1985) A Regra e o Modelo: Sobre a Teoria da Arquitetura e do Urbanismo (tradução de Geraldo Gerson de Souza). São Paulo: Editora Perspectiva, título original: "La Régle et le Modèle: Sur la Théorie de I'Architecture et d'Urbanisme", (1980).

COSTA, L.(1997) Lucio Costa: registro de uma vivência. São Paulo: Empresa das Artes, $1^{\text {a }}$ edição 1995.

DINIZ, A. M. A. \& BATELLA, W. B. O Estado de Minas Gerais e suas Regiões: um resgate histórico das principais propostas oficiais de regionalização. SOCIEDADE \& NATUREZA, Uberlândia, 17 (33): p.73.

FERNANDES, A. \& GOMES, M. A. A. de F. (1998) A pesquisa recente em história urbana no Brasil: percursos e questões. In: PADILHA, Nino (org.). Cidade e Urbanismo: história, teorias e práticas. Salvador: Mestrado em Arquitetura e Urbanismo da FAUFBa.

GOMES, M. A. A. de F. \& LIMA, F. J. M. de. (1999) Pensamento e prática urbanística em Belo Horizonte: 1895-1961. In: LEME, M. C. da S. (org.). Urbanismo no Brasil: 1895-1965. São Paulo: Studio Nobel; FAUUSP; FUPAM. 
. (1996) Pensamento e Pratica Urbanistica em Belo Horizonte. In: IV

Seminario de Historia da Cidade e do Urbanismo, Rio de Janeiro. IV Seminario de Historia da Cidade e do Urbanismo. Rio de Janeiro: PROURB/FAUUFRJ, v. 3.

HOLANDA, S. B. de. (2001) Raízes do Brasil. São Paulo: Companhia das Letras, 220 p., 1 a edição 1936.

LEME, M. C. da S. L.. (org.). (1999) Urbanismo no Brasil: 1895-1965. São Paulo: Studio Nobel; FAUUSP; FUPAM.

LIMA, F. J. M. de. (1994) Bello Horizonte: um passo de modernidade. Salvador: s.n.,1994, Dissertação de Mestrado - FAUFBa.

. (2003) Por uma cidade moderna: Ideários de urbanismo em jogo no concurso para Monlevade e nos projetos destacados da trajetória dos técnicos concorrentes (1931-1943). São Paulo, Tese de Doutorado - FAUUSP.

LIMA, F. J. M. de.(2011) A cidade como um fato urbanistico: João Monlevade. In: CORREIA, T. de B. (Org.). Forma Urbana e Arquitetura de vilas operárias e núcleos residenciais de empresas no Brasil. 1ed .Sao Paulo: Annablume; Fapesp, v. 1, p. 1-298.

LIMA, F. J. M. \& GOMES, M. A. A. F. (2010) Arquitetos e Urbanistas: cidade e formação profissional no Brasil, 1900-1960. In: FREITAS, J. F. B. de. (Org.). Diálogos Urbanismobr. Diálogos Urbanismobr. 1ed .Vitória/ES e Niterói/RJ: EDUFES/UFF, v. 1, p. 211-244.

LIMA, F. J. M. (2009) O Ramal Ferreo de Bello Horizonte revisitado a partir das críticas do MOREL, por Lincoln de Campos Continentino. In: CASTRIOTA, L. de B. (Org.). Arquitetura em Belo Horizonte: Novas perspectivas. Belo Horizonte: Editora da UFMG, v. 1, p.

LIMA, F. J. M. (2009) Urbanismo em Minas Gerais: Olhares de Engenheiros, Arquitetos, Geógrafos e outros planejadores. In: CASTRIOTA, L. de B. (Org.). Arquitetura e Documentação.1ed .Belo Horizonte: IEDS/ANABLUMME, v. 1, p. 1-300.

LIMA, F. J. M. (2010) Urbanismo em Minas Gerais: Pelas Cidades. Juiz de Fora: Editora da UFJF.

LIMA, F. J. M. ; PORTES, R. V. R. ; REZENDE, R. F. (2010). Different visions for the same cities, translations and apropriations of urban ideologies in Minas Gerais, Brazil. In: 14 th IPHS conference: urban transformation: controversies, contrasts and challenges, 2010, Istanbul. Proceedings 2010, Istanbul. Istanbul: ITU, v. 3. p. 209-216. 
. (2009) O Barreiro do Araxá em três tempos: dilemas para a preservação do complexo balneário em Araxá/MG. In: $8^{\circ}$ SEMINARIO DOCOMOMO BRASIL Cidade Moderna e Contemporanea, sintese e paradoxo das artes. Rio de Janeiro: UFRJ/UFF/FIO CRUZ, v. 1. p. 1.

LIMA, F. J. M. ; PORTES, R. V. R. ; REZENDE, R. F. ; BARBOSA, D. M. ; TEPERINO, L. (2007) Urbanismo en Minas Gerais, João Monlevade/M.G.: una Ciudad Jardín Industrial en Brasil (1934-1965). In: V Coloquio Latinoamericano sobre Rescate y Preservación del Patrimonio Industrial, 2007, Buenos Aires. Buenos Aires: CEDODAL, v. 1.

LIMA, F. J. M. ; MARIA, L. ; PIMENTA, N. R. ; CARVALHO, L. C. (2006) Urbanismo em Minas Gerais, idealizaçoes e realizaçoes urbanisticas para as cidades mineiras (1856-1965). In: II Mostra da Universidade Federal de Juiz de Fora/XII Seminário de Iniciação Científica, Juiz de Fora/M.G.

LIMA, F. J. M. (2012) Comparative approaches on urban planning cities history in Minas Gerais, Brazil: theories and methodologies to analyses. In: 15th IPHS Conference: "Cities, nations and regions in planning history". Sao Paulo: FAUUSP, 2012. v. 1. p. 1.

. (2008) Urbanismo em Minas Gerais, sobre as idealizações e as realizações urbanisticas para as cidades mineiras, olhares de engenheiros, arquitetos e outros planejadores (1856-1965). In: ANPUH Minas Gerais. XVI Encontro Regional de História, Belo Horizonte. ANPUH Minas Gerais, v. 1.

. (2005) Urbanismo em Minas Gerais: Sobre as contradições do discurso moderno presentes nas idealizações e realizações urbanísticas do arquiteto Angelo A. Murgel (1932-1942). In: 60 SEMINARIO DOCOMOMO BRASIL: MODERNO E NACIONAL, Niteroi/RJ. $6^{\circ}$ DOCOMOMO - Moderno e Nacional - Arquitetura e Urbanismo. Niteroi/RJ: UFF/PPGAU, v. 1.

. (2005) Urbanismo em Minas Gerais, idealizaçoes e realizaçoes urbanisticas para as cidades mineiras (1856-1965). In: XXIII ENSEA PROJETOS POLÍTICOS PEDAGÓGICOS: NOVAS EXPERIENCIAS, Fortaleza/CE. Anais do XXIII ENSEA PROJETOS POLÍTICOS PEDAGÓGICOS: NOVAS EXPERIENCIAS. Brasília: ABEA /ENSEA- organização, 2005. v. 1.

. (2004) Por uma Cidade Moderna: Ideários de Urbanismo em jogo na trajetória de engenheiros e arquitetos entre os anos 30 e 40 . In: VIII Seminario da historia da cidade e do urbanismo, Niteroi/RJ. Anais VIII SHCU. Niteroi/RJ: UFF, v. 1. 
. (2004) Por uma cidade moderna: Ideários de urbanismo em jogo no concurso para Monlevade e a realização da nova cidade operária (19341960). In: Simposio A organização do territorio pelo capital, o caso das vilas e núcleos gerados por empresas, São Paulo. A Organização do Territóriio pelo Capital: o caso das Vilas e Núcleos gerados por Empresas. Rio de Janeiro/R.J.: Fundação Biblioteca Nacional, 2004. v. 1.

. (2002)Ideários urbanísticos em confronto no concurso para Monlevade.

VII Seminário de História da Cidade e do Urbanismo. Salvador, 15 a 18 de outubro de 2002.

. (2002) Cidade Industrial de Monlevade: visões de urbanismo em jogo. VII CONGRESSO LUSO-AFRO-BRASILEIRO DE CIÊNCIAS SOCIAIS. Rio de Janeiro, 2 a 6 de setembro de 2002.

.(2002) Questões de saneamento e urbanismo na atuação do engenheiro Lincoln Continentino em Minas Gerai. In: V CONGRESSO DE ENGENHARIA CIVIL, 2002, Juiz de fora. V CONGRESSO DE ENGENHARIA CIVIL.

.(2001)Problemas de Urbanismo em Minas Gerais nos anos 30. IX

Encontro Nacional da ANPUR: Ética, planejamento e construção democrática do espaço. Rio de Janeiro, 28 de maio a 1 de junho de 2001.

- (2000) As noções urbanísticas do engenheiro Francisco Baptista de Oliveira. In: VI SEMINÁRIO DE HISTÓRIA DA CIDADE E DO URBANISMO, Natal/RN. VI SEMINÁRIO DE HISTÓRIA DA CIDADE E DO URBANISMO. Natal/RN: Universidade Federal do Rio Grande do Norte - UFRN, v. 1.

. (1999) Cidade Operária de Monlevade: novos conceitos de morar. III Seminário DOCOMOMO Brasil. São Paulo, 8 a 11 de dezembro de 1999.

. (1998) O Ramal Ferreo de Bello Horizonte revisitado a partir das criticas

do MOREL: 1894/1964. In: V Seminario de Historia da Cidade e do Urbanismo, 1998, Campinas. V Seminario de Historia da Cidade e do Urbanismo. Campinas: PUC Campinas.

- (1993) A um passo da Modernidade na Bello Horizonte do final do

Seculo XIX. In: V Encontro Nacional da ANPUR, Belo Horizonte. V Encontro Nacional da ANPUR. Belo Horizonte: ANPUR, v. 3.

LIMA, F. J. M. de et al. (2007) Caderno do Plano Diretor Participativo de Chácara/M.G.. Juiz de Fora, UFJF, Prefeitura Municipal de Chácara.

(2007) Caderno do Plano Diretor Participativo de Coronel Pacheco/M.G.. Juiz de Fora, UFJF, Prefeitura Municipal de Coronel Pacheco. 
- (2007) Caderno do Plano Diretor Participativo de Mar de

Espanha/M.G.. Juiz de Fora, UFJF, Prefeitura Municipal de Mar de Espanha.

. (2007) Caderno do Plano Diretor Participativo de Rio Preto/M.G.. Juiz de Fora, UFJF, Prefeitura Municipal de Rio Preto.

- (2007) Caderno do Plano Diretor Participativo de Santana do

Deserto/M.G.. Juiz de Fora, UFJF, Prefeitura Municipal de Santana do Deserto. . (2007) Caderno do Plano Diretor Participativo de Simão Pereira/M.G..

Juiz de Fora, UFJF, Prefeitura Municipal de Simão Pereira.

SAlgueiro, H. A. S. (org.). (2001) Cidades Capitais do Século XIX:

Racionalidade, Cosmopolitismo, e Transferência de Modelos. São Paulo:

Editora da Universidade de São Paulo.

.(1997) Engenheiro Aarão Reis: o progresso como missão. Belo Horizonte:

Fundação João Pinheiro; Centro de Estudos Históricos e Culturais.

TAFURI, M. (1979) Teorias e história da arquitectura. Lisboa: Editorial Presença;

São Paulo: Martins Fontes.

_. (1985) Projecto e Utopia: arquitectura e desenvolvimento do capitalismo (tradução de Conceição Jardim e Eduardo Nogueira). Lisboa: Editorial Presença, 1985, 122 p., título original: "Progetto e Utopia".

VEYNE, P. (1995) Como se escreve a história; Foucault revoluciona a história

(tradução de Alda Baltar e Maria Auxiliadora Kneipp). Brasília: Editora da Universidade de Brasília, título original: "Comment on écrit I'histoire", (1971), "Foucault révolutionne I' histoire" (1978).

VILLAÇA, F. (1998) Espaço intra-urbano no Brasil. São Paulo: Studio Nobel/FAPESP/Lincoln Institute.

ZUCCONI, G. (1989) La città contesa: dagli ingegneri sanitari agli urbanisti: (1885-1942). Milano: Jaca Book. 